\title{
ESTUDOS AMBIENTAIS DA BACIA DO RIO DOCE NO CONTEXTO PRÉ E PÓS- ROMPIMENTO DA BARRAGEM DE REJEITOS DE MINERAÇÃO
}

\author{
ENVIRONMENTAL STUDIES OF THE RIO DOCE WATERSHED IN THE CONTEXT BEFORE AND AFTER \\ FAILURE OF MINING TAILINGS DAM
}

\section{Raphaela Martins de Carvalho ${ }^{1 *}$, Vanielle Aparecida do Patrocinio Gomes ${ }^{2}$, Mayra Jankowsky ${ }^{3}$, \& Rodrigo Randow de Freitas ${ }^{4}$}

\footnotetext{
${ }^{1}$ Fundação de Desenvolvimento da Pesquisa do Agronegócio. ${ }^{2,4}$ Centro Universitário Norte do Espírito Santo da Universidade Federal do Espírito Santo. ${ }^{3}$ Instituto de Pesca de São Paulo. ${ }^{1 *}$ rapha_carvalhoo@ $@$ hotmail.com ${ }^{2}$ vaniellea.gomes@hotmail.com ${ }^{3}$ mayra.jankowsky@ gmail.com ${ }^{4}$ rodrigo.r.freitas@ufes.br
}

\section{ARTIGO INFO.}

Recebido em: 13.01.2021

Aprovado em: 29.03.2021

Disponibilizado em: 08.04.2021

Palavras-chave:

Impacto ambiental; bibliometria; meio biótico.

\section{KEYWORDS:}

Environmental impact; bibliometrics; biotic factors.

*Autor Correspondente: Carvalho, R. M.

\section{RESUMO}

A Bacia Hidrográfica do Rio Doce configura-se como um mosaico complexo de paisagens, uma herança dos processos geo-históricos de ocupação e exploração dos seus recursos naturais. Nessa conjuntura, o maior impacto ambiental registrado nessa bacia ocorreu em 2015, com o rompimento da barragem de rejeitos de Fundão, localizada no município de Mariana - MG. Dessa forma, esse estudo teve por objetivo desenvolver uma análise bibliométrica das publicações relacionadas à atividade pesqueira e aquícola na bacia, com ênfase nos estudos ambientais relacionados ao meio biótico, a fim de melhor compreender as mudanças nas temáticas das pesquisas e as lacunas no conhecimento no período anterior e posterior ao ocorrido. Para isso, foram utilizados métodos bibliométricos na avaliação geral dos artigos e análise de conteúdo nos trabalhos relacionados especificamente ao meio biótico. Como resultados, observa-se o aumento do número de publicações após o desastre e o aprofundamento da visão desse cenário, bem como o maior interesse da comunidade internacional em estudar a área. Também, constata-se a mudança do foco dos trabalhos do meio biótico, os quais passam a abordar prioritariamente os impactos promovidos pelos rejeitos nas comunidades e no seu entorno. Além disso, destaca-se o reduzido conhecimento do meio biótico na região, principalmente no alto Rio Doce no período anterior e no médio no posterior. Assim, evidencia-se a importância da intensificação dos estudos nessa bacia, visando à produção de conhecimento para uma gestão mais sustentável dos seus recursos naturais.

\section{ABSTRACT}

The Rio Doce Watershed is a complex mosaic of landscapes, a legacy of the geo-historical processes of occupation and exploitation of its natural resources. In this context, the greatest environmental impact recorded in this basin occurred in 2015, with the rupture of the tailings dam in Fundão, located in the municipality of Mariana - MG. Thus, this study aimed to develop a bibliometric analysis of publications related to fishing and aquaculture activity in the basin, with emphasis on environmental studies related to the biotic factors, in order to better understand how the themes changed in research and gaps in knowledge in the period before and after the disaster. For this, bibliometric methods were used in the general evaluation of articles and content analysis in articles related specifically to the biotic factors. As a result, there is an increase in the number of articles published after the disaster and the deepening of the vision of this scenario, as well as the greater interest of the international community in studying the area. Also, there is a change in the focus of the articles of the biotic factors, which starts to address primarily the impacts caused by tailings in the communities and their surroundings. In addition, there is a gap in the knowledge of the biotic factors in the region, mainly in the upper Rio Doce in the previous period and in the middle in the later. Thus, it is evident the importance of intensifying studies in this basin, aiming at the production of knowledge for a more sustainable management of its natural resources.

\section{INTRODUÇÃO}



"Pesca e Aquicultura: Gestão, Política e Inovação", 63-84.

A Bacia Hidrográfica do Rio Doce localiza-se na região sudeste do Brasil e apresenta uma população residente de aproximadamente 3,5 milhões de habitantes, compondo 226 municípios (Viana, 2016). Seus recursos hídricos desempenham um papel fundamental para o leste mineiro e o noroeste capixaba, uma vez que fornecem a água necessária aos usos doméstico, agropecuário, industrial e geração de energia elétrica (Espindola et al., 2016). À vista disso, essa bacia apresenta um histórico de intensos impactos ambientais, ligados principalmente ao desmatamento, transformação do uso do solo, poluição da água, introdução de espécies não nativas, caça e atividade pesqueira ilegal (Coelho, 2009; Felippe et al., 2016). Com isso, a perda da integridade ambiental sofrida pela bacia afeta tanto o uso de seus recursos pelo ser humano quanto a sua biodiversidade (Viana, 2016). Também, a avaliação e a mitigação dos impactos apresentam-se como tarefas difíceis, dado a escassez de conhecimento da área (Knopff et al., 2020).

Neste contexto, muitas atividades antrópicas, como a pesca, compreendem ações altamente dependentes das condições naturais, sendo caracterizadas como sistemas socioecológicos, ou seja, com múltiplas interações sociais e ecossistêmicas (Berkes et al., 2003). Assim, ao transformá-las em objeto de análise, ocorrem implicações teóricas e metodológicas que necessitam de uma abordagem interdisciplinar e sistêmica, permitindo considerar o meio ambiente, as realidades sociais e as práticas e técnicas em um mesmo esforço de compreensão (Raynaut, 2002). Dessa forma, para o estudo dos aspectos ambientais da Bacia do Rio Doce, torna-se premissa indispensável o levantamento de informações de um amplo conjunto de fatores, que envolvam de forma direta ou indireta a distribuição, situação e capacidade de renovação dos recursos naturais, uma vez que o seu meio biótico e abiótico têm sido submetidos a diversas implicações (Felippe et al., 2016).

Como destaque de atividade impactante nessa região, no dia 05 de novembro de 2015 , houve o rompimento da barragem de Fundão localizada no município de Mariana - MG. O barramento, classificado como de alto potencial de dano ambiental, era destinado a receber e armazenar o rejeito gerado pela atividade de beneficiamento de minério de ferro, e seu rompimento causou efeitos em cadeia, ocasionando a devastação do distrito de Bento Rodrigues, com a morte de 19 pessoas, bem como os impactos da lama por cerca de $850 \mathrm{~km}$ ao longo do rio Doce, chegando até o oceano Atlântico (Espindola et al., 2016). Esse desastre trouxe intensas implicações para os aspectos físicos, bióticos e socioeconômicos da bacia, e entre os danos mais significativos encontra-se a morte de fauna aquática e a paralisação das atividades econômicas desenvolvidas no rio Doce pelas comunidades locais (Lima et al., 2020).

Desse modo, essa pesquisa teve por objetivo efetuar uma análise bibliométrica das publicações relacionadas à atividade pesqueira e aquícola na Bacia do Rio Doce, com ênfase nos estudos ambientais relacionados ao meio biótico. As publicações foram contextualizadas no período anterior e posterior ao rompimento da barragem de rejeitos de mineração de Fundão, a fim de melhor compreender as mudanças nas temáticas das pesquisas e as lacunas no conhecimento.

\section{Metodologia}


A bibliometria utiliza variados métodos e procedimentos associados a ferramentas estatísticas para entender comportamentos de fenômenos, tendo por base diferentes trabalhos e fontes científicas (Bartolini et al., 2019; Mishra et al., 2016). Essa metodologia tem sido utilizada para investigar tendências de pesquisa em campos diversos (e.g. Hu et al., 2010). Assim, neste estudo foram aplicados métodos bibliométricos para analisar quantitativamente e qualitativamente os estudos relacionados à atividade pesqueira e aquícola na Bacia do Rio Doce e seus aspectos ambientais do meio biótico.

Para isso, elaborou-se uma lista com diversos termos de busca em três idiomas (português, inglês e espanhol), e a mesma foi ampliada e validada por oito especialistas da área, onde se obteve um método consolidado para a aplicação nas bases de dados (Apêndice 1). Ainda, visando filtrar os estudos especificamente relacionados ao rio Doce e sua bacia, estas palavras foram consideradas como fixas na busca, combinando individualmente com os demais termos, por meio do conectivo "e", para abranger o maior número possível de artigos científicos, exclusivamente. A procura pelos trabalhos ocorreu entre junho e setembro de 2020.

As bases de dados para a realização das buscas foram consideradas segundo sua abrangência para uma gama de artigos de alta relevância, provenientes de periódicos de maior visibilidade na comunidade acadêmica (Quadro 1). Além disso, foram selecionados somente os artigos que estavam disponíveis e liberados para download.

Quadro 1. Bases de dados utilizadas

\begin{tabular}{cc}
\hline Academic Resource Index - ResearchBib & Pubmed \\
Bioline International & Redalyc AmeliCA \\
CAB Direct & Scientific Electronic Library Online - SciELO \\
Directory of Open Access Journals & Science Direct \\
Evidence-Based Medicine - EBM & Scopus \\
Embase & Springer \\
Google Scholar & Sumários \\
Medline & WorldCat \\
Microsoft Academic Search & Web of Science - WOS \\
Online Journals Search Engine & \\
\hline
\end{tabular}

Após a identificação de todos os artigos com os termos de busca nas bases, realizou-se a exclusão dos trabalhos duplicados, bem como a verificação da área de estudo por meio da leitura dos títulos e resumos, sendo eliminados os que não atenderam à área geográfica definida. Em seguida, foram realizadas análises quantitativas, mapeando os anos das publicações e o número de estudos por base de dados. Também, efetuou-se uma categorização das palavras dos títulos dos artigos publicados nos dois anos que imediatamente antecederam o desastre (2014 e 2015) e nos dois anos mais recentes após o desastre (2019 e 2020), de forma individual para cada ano, a fim de comparar as tendências das publicações nesses períodos. Para tanto, seis especialistas classificaram os termos que apareceram ao menos duas vezes, utilizando o método de matriz SWOT (Strenghts, Weaknesses, Opportunities e Threats), e os pontos de convergência que surgiram em mais de 50\% das matrizes foram mantidos. A compreensão dos fatores externos (oportunidades e ameaças) e dos fatores internos (pontos fortes e pontos fracos) pode colaborar para o desenvolvimento de um futuro almejado (Silveira, 2001). 
Citação (APA): Carvalho, R. M., Gomes, V. A. P, Jankowsky, M., \& Freitas, R. R. (2021). Estudos ambientais da Bacia do Rio Doce no contexto pré e pós-rompimento da barragem de rejeitos de mineração. Brazilian Journal of Production Engineering, 6(8), Edição Especial "Pesca e Aquicultura: Gestão, Política e Inovação", 63-84.

Posteriormente, estabeleceu-se o número de artigos que deveriam ser explorados minuciosamente em cada uma das bases. Considerando o nível de confiança, a população total (número de artigos nas bases) e a margem de erro, a amostra foi dimensionada por meio de cálculo amostral, estabelecido pela equação (Dupont \& Plummer, 1990):

$$
n=\frac{Z^{2} \cdot\left(\frac{x}{n}\right) \cdot\left[1-\left(\frac{x}{n}\right)\right] \cdot N}{(N-1) \cdot e^{2}+Z^{2} \cdot\left(\frac{x}{n}\right) \cdot\left[1-\left(\frac{x}{n}\right)\right]}
$$

Onde, $n$ representa o tamanho da amostra que se deseja estabelecer; $N$ é o tamanho da população; $e$ refere-se ao erro amostral; $x / n$ é a proporção estimada do item pesquisado na amostra (\%); e $Z$ o valor da abscissa da curva normal associada ao nível de confiança. $\mathrm{O}$ erro amostral considerado aceitável foi de 5\%, sem a previsão estimada do tamanho da amostra utilizou-se o valor de 50\%, e o nível de confiança aplicado foi de $90 \%$.

A partir da definição do número de artigos a serem avaliados para cada base de dados, foram selecionadas as publicações com maior número de citação e lidas em sua íntegra. As bases que apresentaram artigos disponíveis para download e o número de citações foram: Embase, Google Scholar, Microsoft Academic, Science Direct, Scientific Electronic Library Online, Scopus e Web of Science. Posteriormente, para facilitar a análise, os artigos foram separados em três categorias: meio físico, meio biótico, com a subdivisão ictiofauna e pesca, e meio socioeconômico. Então, realizou-se uma análise de conteúdo nos artigos que trazem os estudos do meio biótico, a fim de analisar as tendências das publicações nessa área, bem como identificar as lacunas de conhecimento. Nesta etapa da análise, não foram descritos os artigos relacionados diretamente à ictiofauna e a atividade pesqueira, uma vez que eles foram analisados separadamente e se apresentam previamente detalhados na publicação "Peixes e pesca na Bacia do Rio Doce, uma análise bibliométrica" (Jankowsky et al., 2021), assim como os cinco artigos relacionados à biogeografia e paleontologia do meio biótico da região, por não impactarem na análise dentro do contexto do desastre considerado, a saber: Behling et al. (2002); Colombi et al. (2010); França et al. (2013); França et al. (2016); Saiter et al. (2016).

\section{RESUltados E DiscuSSÃo}

\subsection{Análise geral das publicações}

A procura dos artigos científicos nos bancos de dados, utilizando todos os termos de busca, retornou inicialmente 720 trabalhos, publicados entre 1969 e julho de 2020. Após a eliminação das publicações repetidas e a verificação da área de estudo, obteve-se um total de 389 artigos. A fim de propiciar um panorama geral do número de trabalhos, a Tabela 1 apresenta uma classificação temporal dos artigos selecionados, referente ao período anterior e posterior ao rompimento da barragem.

Tabela 1. Número total de artigos publicados antes e depois do desastre

\begin{tabular}{cc}
\hline Ano de publicação & Número de artigos \\
\hline $1969-2015$ & 136 \\
$2016-2020$ & 253 \\
\hline
\end{tabular}


Nota-se um crescimento considerável do número de artigos relacionados à atividade pesqueira e aquícola na Bacia do Rio Doce após o ano de 2015, quando ocorreu o rompimento da barragem de Fundão. Realizando uma comparação, nos quase cinco anos após o desastre publicou-se aproximadamente o dobro do número de artigos científicos produzidos nos 47 anos anteriores, demonstrando um maior interesse dos pesquisadores em estudar a região depois desse acontecimento.

Das 19 bases de dados selecionadas, apenas duas não retornaram artigos científicos: Bioline International e WorldCat. Entre as que apresentaram resultados, observa-se o maior número de trabalhos publicados antes do rompimento nas bases Scientific Electronic Library Online (37), Redalyc AmeliCA (21), Web of Science (21) e Google Scholar (18), e depois nas bases Scopus (84), Web of Science (48) e Google Scholar (43) (Figura 1). Isso mostra, de acordo com o enfoque das bases de dados, que após o desastre houve uma ampliação da área de abrangência das publicações, passando de um contexto mais regional da América Latina para o âmbito global, o que infere um aumento no entusiasmo da comunidade científica internacional em desenvolver estudos na região.

Figura 1. Número de artigos publicados antes e depois do desastre por base de dados

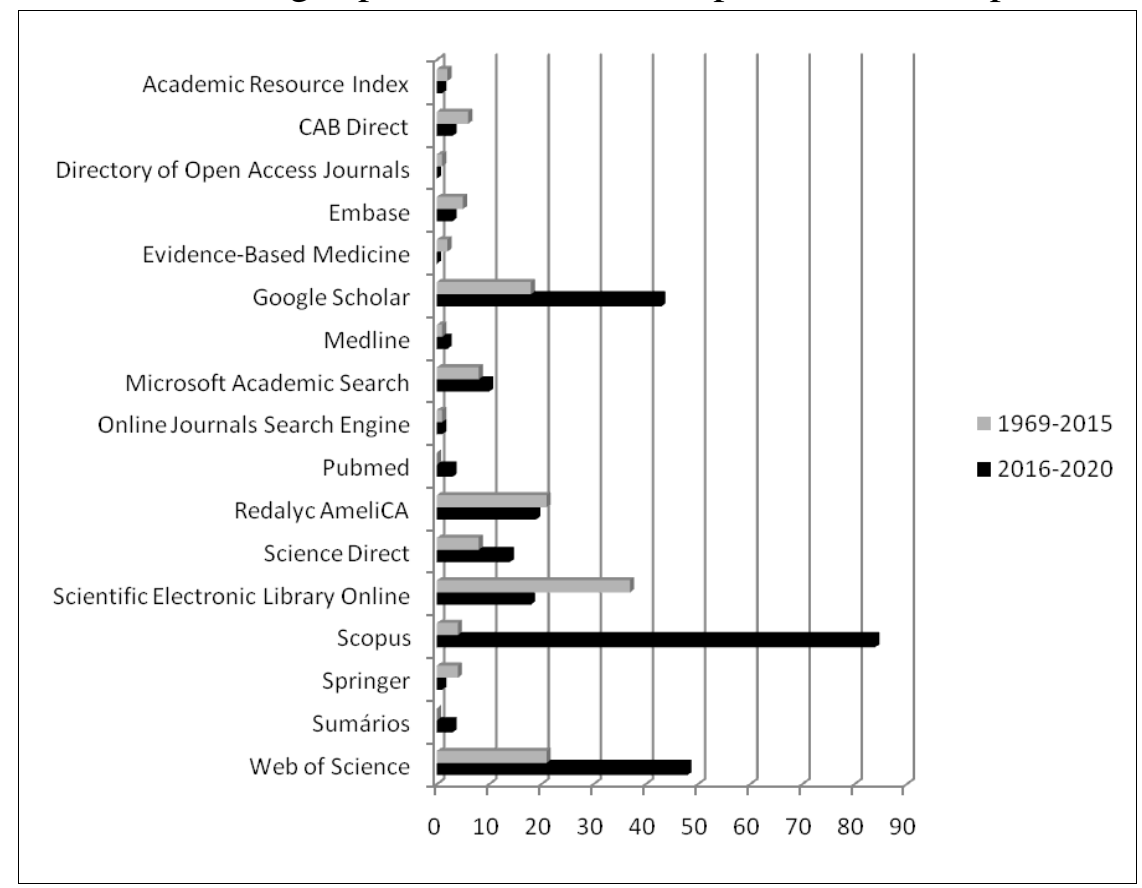

Em relação às palavras dos títulos dos artigos, constata-se claramente o menor número (29) de palavras repetidas nos anos de 2014 e 2015, bem como o aparecimento de poucas fraquezas e ameaças como foco das pesquisas realizadas (Figura 2). Entretanto, após o rompimento da barragem, há uma drástica alteração do cenário geral das publicações. Em 2019 e 2020, o enfoque nas fraquezas e ameaças apresenta-se similar a fortalezas e oportunidades, e com um maior número (135) de palavras repetidas nos títulos (Figura 3). Além disso, neste período há mais publicações, consequentemente uma visão mais aprofundada do cenário de estudo, o que se reflete na melhor percepção das fortalezas, oportunidades, fraquezas e ameaças. 
Citação (APA): Carvalho, R. M., Gomes, V. A. P, Jankowsky, M., \& Freitas, R. R. (2021). Estudos ambientais da Bacia do Rio Doce no contexto pré e pós-rompimento da barragem de rejeitos de mineração. Brazilian Journal of Production Engineering, 6(8), Edição Especial "Pesca e Aquicultura: Gestão, Política e Inovação", 63-84.

Figura 2. Resultado para a análise SWOT das publicações de 2014 e 2015

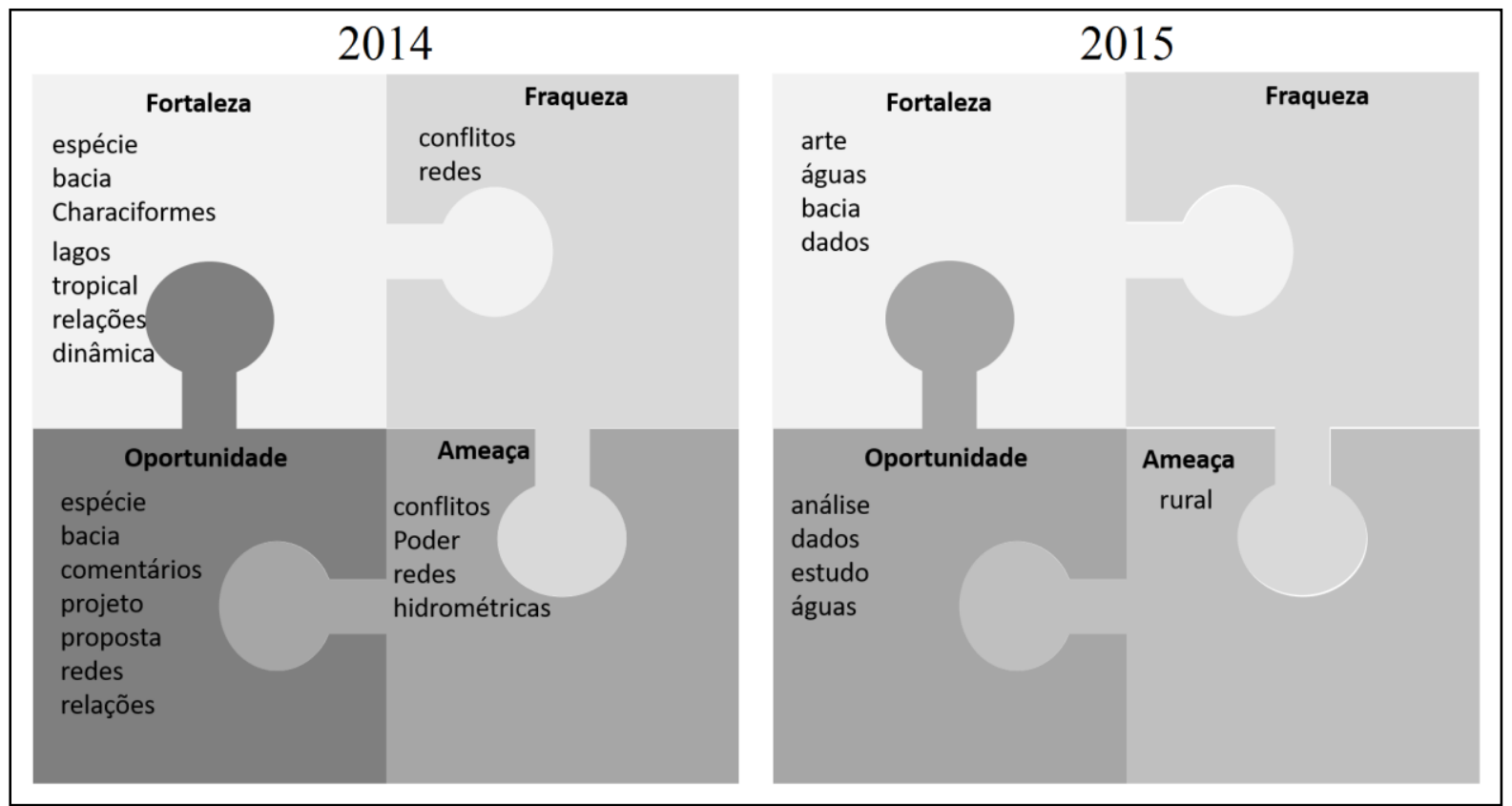

Figura 3. Resultado para a análise SWOT das publicações de 2019 e 2020

\begin{tabular}{|c|c|c|c|c|c|c|c|}
\hline \multicolumn{4}{|c|}{2019} & \multicolumn{4}{|c|}{2020} \\
\hline \multicolumn{2}{|l|}{ Fortaleza } & \multicolumn{2}{|c|}{ Fraqueza } & \multicolumn{2}{|c|}{ Fortaleza } & \multicolumn{2}{|c|}{ Fraqueza } \\
\hline $\begin{array}{l}\text { florestal } \\
\text { ambientais } \\
\text { história } \\
\text { associados } \\
\text { indigena } \\
\text { peixes } \\
\text { Characidium } \\
\text { percepção } \\
\text { Mata Atlântica } \\
\text { Geophagus brasiliens }\end{array}$ & $\begin{array}{l}\text { ambiental } \\
\text { participação } \\
\text { água (s) } \\
\text { biomassa } \\
\text { bacia } \\
\text { costeira } \\
\text { rio } \\
\text { espécie } \\
\text { Abrolhos } \\
\text { sis }\end{array}$ & $\begin{array}{l}\text { barragem(s) } \\
\text { sedimentos } \\
\text { desastre } \\
\text { impacto } \\
\text { Fundão } \\
\text { medo } \\
\text { colapso } \\
\text { contaminação } \\
\text { afetada }\end{array}$ & $\begin{array}{l}\text { cidade } \\
\text { falha } \\
\text { resíduos } \\
\text { rompimento } \\
\text { mineração } \\
\text { metais } \\
\text { minério } \\
\text { Samarco } \\
\text { rejeitos }\end{array}$ & $\begin{array}{l}\text { água } \\
\text { ambiental } \\
\text { ambiental(is) } \\
\text { bacia } \\
\text { espécies } \\
\text { florestal } \\
\text { Mata Atlântica } \\
\text { Astyanax lacust }\end{array}$ & $\begin{array}{l}\text { habitat } \\
\text { histórica } \\
\text { marinho } \\
\text { nativas } \\
\text { peixes } \\
\text { solos }\end{array}$ & $\begin{array}{l}\text { afetados } \\
\text { arsênico } \\
\text { barragem } \\
\text { contaminação } \\
\text { desastre } \\
\text { efeitos } \\
\text { expostos } \\
\text { extinção } \\
\text { falha }\end{array}$ & $\begin{array}{l}\text { ferro } \\
\text { Fundão } \\
\text { impacto(s) } \\
\text { metais } \\
\text { pós-desastre } \\
\text { rejeitos } \\
\text { Samarco } \\
\text { sedimentos }\end{array}$ \\
\hline \multicolumn{2}{|c|}{ Oportunidade } & \multicolumn{2}{|c|}{ Ameaça } & \multicolumn{2}{|c|}{ Oportunidade } & \multicolumn{2}{|c|}{ Ameaça } \\
\hline $\begin{array}{l}\text { avaliação } \\
\text { políticas públicas } \\
\text { análise } \\
\text { sensoriamto remoto } \\
\text { biomassa } \\
\text { água } \\
\text { caracterização } \\
\text { estudantes } \\
\text { dados } \\
\text { proteção } \\
\text { estratégia }\end{array}$ & $\begin{array}{l}\text { percepção } \\
\text { estudo } \\
\text { rio } \\
\text { modelagem } \\
\text { pesquisa } \\
\text { movimentos } \\
\text { sociais } \\
\text { potencial } \\
\text { participação } \\
\text { relação }\end{array}$ & $\begin{array}{l}\text { barragens }(\mathrm{m}) \\
\text { colapso } \\
\text { contaminação } \\
\text { efeitos } \\
\text { falha } \\
\text { ferro } \\
\text { metais } \\
\text { minas } \\
\text { mineração }\end{array}$ & $\begin{array}{l}\text { minério } \\
\text { rejeitos } \\
\text { resíduos } \\
\text { riscos } \\
\text { rompimento } \\
\text { ruptura } \\
\text { Samarco } \\
\text { seca } \\
\text { sedimentos }\end{array}$ & $\begin{array}{l}\text { análise } \\
\text { avaliação } \\
\text { econômico } \\
\text { estudo } \\
\text { histórica } \\
\text { investigação } \\
\text { método(s) } \\
\text { mudanças } \\
\text { uso }\end{array}$ & na & $\begin{array}{l}\text { arsênico } \\
\text { barragem } \\
\text { colapso } \\
\text { contaminação } \\
\text { econômico } \\
\text { extinção } \\
\text { falha } \\
\text { ferro } \\
\text { habitat }\end{array}$ & $\begin{array}{l}\text { impacto(s) } \\
\text { metais } \\
\text { mineração } \\
\text { minério } \\
\text { mudanças } \\
\text { rejeitos } \\
\text { ruptura } \\
\text { Samarco } \\
\text { sedimentos }\end{array}$ \\
\hline
\end{tabular}

\subsection{Análise dos estudos ambientais do meio biótico}

Com o desenvolvimento do cálculo para a definição da amostra, obteve-se o resultado de um adequado tamanho amostral de 278 artigos, os quais foram divididos em meio físico, socioeconômico e biótico, onde este último apresentou o maior número de estudos (113). Destes, 50 artigos tratam especificamente da ictiofauna e atividade pesqueira e foram detalhados por Jankowsky et al. (2021), enquanto os outros 63 estudos estão listados no Apêndice 2. 

"Pesca e Aquicultura: Gestão, Política e Inovação", 63-84.

\subsubsection{Publicações pré-rompimento da barragem de rejeitos de mineração}

A Bacia Hidrográfica do Rio Doce apresenta 86\% do seu território no estado de Minas Gerais e $14 \%$ no Espírito Santo, e sua área pode ser dividida em três unidades regionais: alto, médio e baixo rio Doce (Coelho, 2009). A região do alto rio Doce localiza-se a montante da confluência dos rios Doce e Piracicaba, e envolve parte das nascentes/ bacias que vertem da Serra do Espinhaço, em Minas Gerais; o médio rio Doce possui seus limites a jusante da confluência dos rios Doce e Piracicaba até a divisa dos estados de Minas Gerais e Espírito Santo, e abrange parte do oeste e noroeste da bacia; e o baixo rio Doce abrange a porção capixaba, sendo delimitada a oeste pelas colinas baixas próximas à Colatina (Coelho, 2009).

No baixo rio Doce, três estudos foram desenvolvidos no período anterior ao desastre. No primeiro, realizado especificamente no município de Linhares, Cavati e Fernandes (2008) relataram a presença de 86 e 83 taxa de algas perifíticas na lagoa Juparanã e no rio Pequeno, respectivamente, sem variação espacial da estrutura da comunidade e das variáveis limnológicas entre os dois ecossistemas. Além disso, Salvador e Cavallari (2014) descreveram uma nova espécie de gastrópode pulmonado, Leiostracus faerie, encontrada na região do rio Doce e depositada em uma coleção na Alemanha, onde evidenciaram a falta de conhecimento dessa fauna e reforçaram a importância das coleções de museus no estudo da biodiversidade e em medidas de conservação. No último trabalho desenvolvido nessa região, Mayorga et al. (2020) levantaram as informações sobre os encalhes de cetáceos para o estado do Espírito Santo, com exceção das baleias jubarte, de 1975 a setembro de 2015, onde registraram 461 encalhes, abrangendo 20 espécies, as quais compreendem quase metade da diversidade de cetáceos conhecida no Brasil. Apesar desta publicação ter ocorrido após ao desastre, os dados referem-se ao momento anterior, por isso foi considerada neste tópico para a análise dos estudos ambientais do meio biótico.

A unidade regional mais estudada nesse período corresponde ao médio rio Doce, onde 18 pesquisas foram desenvolvidas no total. Entre elas, Pitelli et al. (2014) avaliaram a composição específica e a área de colonização das macrófitas aquáticas no reservatório da Usina Hidrelétrica Eliezer Batista, formado pelo represamento do rio Doce no município de Aimorés, onde constataram uma boa riqueza, com 31 espécies, pertencentes a 16 famílias, destacando-se o aguapé e a salvínia.

Também, três estudos analisaram bioindicadores para avaliar a qualidade das águas do trecho médio da bacia. Marques et al. (1999a) investigaram os padrões de distribuição e abundância de larvas da família Chironomidae (Diptera, Insecta), em locais onde as atividades de mineração, garimpo, siderurgia e monocultura de Eucalyptus spp. contribuem para a degradação ambiental e a baixa qualidade da água, e as estações verificadas como de pior qualidade indicaram estresse ambiental devido ao enriquecimento orgânico da água por ação antrópica. Medeiros et al. (2012) determinaram os níveis de indicadores microbianos de qualidade da água e espécies de leveduras presentes em ambientes de água doce, por meio de amostragem de regiões com diferentes níveis de impactos antrópicos, onde constataram nos mesmos ambientes as maiores contagens de leveduras e de bactérias coliformes e heterotróficas, visto que estes locais apresentavam um grande fluxo de resíduos domésticos e 
Citação (APA): Carvalho, R. M., Gomes, V. A. P, Jankowsky, M., \& Freitas, R. R. (2021). Estudos ambientais da Bacia do Rio Doce no contexto pré e pós-rompimento da barragem de rejeitos de mineração. Brazilian Journal of Production Engineering, 6(8), Edição Especial "Pesca e Aquicultura: Gestão, Política e Inovação", 63-84.

industriais. Marques e Barbosa (2001) avaliaram a qualidade da água dessa região utilizando a comunidade bentônica de macroinvertebrados, onde classificaram as águas de 20 estações de amostragem em condição ruim, alta ou intermediária, fornecendo uma ferramenta importante para auxiliar os tomadores de decisão na definição de estratégias de restauração/ conservação, bem como para o monitoramento da biodiversidade local.

A área mais conhecida dentro do médio rio Doce, com 14 publicações, corresponde ao Parque Estadual do Rio Doce (PERD) e seus arredores. Na primeira pesquisa desenvolvida nesses locais, Marques et al. (1999b) determinaram algumas das características limnológicas em duas lagoas com diferentes usos e estados de conservação (Carioca - dentro do PERD, e Barra fora do PERD), e compararam a comunidade de macroinvertebrados bentônicos, onde a lagoa Carioca, além de apresentar maior riqueza de taxa, mostrou uma comunidade melhor estruturada em termos de grupos funcionais de alimentação, evidenciando a importância da área protegida.

Em 2004, Petrucio e Barbosa (2004) estimaram as taxas de produção de fitoplâncton e bacterioplâncton junto das concentrações de carbono, nitrogênio e fósforo em quatro corpos hídricos, sendo dois dentro do PERD (lagoas Dom Helvécio e Carioca) e dois nos seus arredores (lagoas Águas Claras e Amarela). Entre as lagoas selecionadas, a Amarela apresentou as maiores concentrações de nutrientes e a maior produção bacteriana. Também medindo a produção de fitoplâncton e bacterioplâncton, em 2006, Petrucio et al. (2006) estudaram sete lagoas, duas dentro do PERD (Dom Helvécio e Carioca) e cinco em seu entorno (Amarela, Águas Claras, Barra, Jacaré e Palmeirinha), e os resultados indicaram que as estações chuvosa e seca influenciaram as produções de forma oposta, onde no verão o metabolismo heterotrófico aumentou, e decaiu no inverno.

Em 2008, Medeiros et al. (2008) investigaram a ocorrência e a frequência de espécies de levedura em quatro ambientes de água doce com diferentes condições de preservação da água, bem como testaram a resistência de espécies que podem crescer a $37^{\circ} \mathrm{C}$ em medicamentos antifúngicos. O número de espécies de levedura foi maior em rios do que em lagoas, visto que eles são submetidos a diferentes tipos de influência humana, como pecuária, mineração e, efluentes domésticos e industriais de muitas cidades. Em 2010, Ferreira et al. (2010) analisaram a diferença na cobertura vegetal de três lagoas do PERD (Dom Helvécio, Gambazinho e Preta), onde foram registradas 37 espécies, e verificou-se que a composição da cobertura vegetal diferiu entre as lagoas estudadas, sugerindo que cada uma constitui uma "ilha" em termos de diversidade. Ainda em 2010, Peixoto et al. (2010) registraram as primeiras espécies exóticas para a comunidade zooplanctônica nas lagoas Dom Helvécio e Carioca (dentro do PERD), e Jacaré e Águas Claras (próximas ao PERD), sugerindo a provável introdução dessas espécies por responsabilidade humana, relacionada à introdução de peixes em lagos do médio rio Doce.

Em 2011, Pivari et al. (2011) compararam a composição e ocorrência de espécies de macrófitas aquáticas dentro (áreas protegidas) e fora (áreas não protegidas) do PERD, onde foram constatadas 184 espécies pertencentes a distintos grupos taxonômicos, indicando que o parque resguarda $74 \%$ das espécies de macrófitas aquáticas encontradas, enquanto os outros 
Citação (APA): Carvalho, R. M., Gomes, V. A. P, Jankowsky, M., \& Freitas, R. R. (2021). Estudos ambientais da Bacia do Rio Doce no contexto pré e pós-rompimento da barragem de rejeitos de mineração. Brazilian Journal of Production Engineering, 6(8), Edição Especial "Pesca e Aquicultura: Gestão, Política e Inovação", 63-84.

26\% estão desprotegidas, pois não ocorrem nessa unidade de conservação. Já em 2012, Brandão et al. (2012) produziram informações sobre as flutuações de longo prazo da população de Daphnia laevis na lagoa Jacaré, localizada próxima ao PERD, e os resultados indicaram que as mudanças nas características físicas e químicas da água relacionadas com os períodos de estratificação e circulação da lagoa podem influenciar diretamente (temperatura, fósforo total) ou indiretamente (disponibilidade de alimento, presença de predadores, eclosão de efípios) na flutuação dessa população. Nesse mesmo ano, Morais et al. (2012) avaliaram se a lâmina d'água total de 16 lagoas vinha se mantendo nas últimas décadas, em uma área de plantação de eucalipto e outra de Mata Atlântica, bioma preservado dentro do PERD, e foi observada uma constância hidrológica de todos os sistemas, bem como dos serviços que este conjunto de lagos presta à sociedade e à biodiversidade de seu entorno.

Em 2013, Barros et al. (2013) colaboraram no conhecimento da diversidade fitoplanctônica deste complexo de lagoas, apresentando os resultados de um inventário de algas em 18 corpos hídricos, sendo oito no PERD e 10 ao redor dele, onde foram registrados 481 taxa, aumentando a diversidade fitoplanctônica total conhecida da região em $80 \%$. Também neste ano, Miranda et al. (2013) investigaram as possíveis causas da redução do número de espécies da comunidade zooplanctônica em três lagoas situadas dentro do PERD (Dom Helvécio, Gambazinho e Carioca) e quatro lagoas localizadas em áreas vizinhas com monocultura de Eucalyptus (Palmeirinha, Jacaré, Amarela e Águas Claras), onde associaram à ação sinérgica de fatores como: a introdução de espécies exóticas de peixes, mudanças no clima, mau uso do solo (especialmente a expansão desordenada dos monocultivos de Eucalyptus), bem como a falta de um plano estratégico voltado ao desenvolvimento econômico, socioambiental e a conservação integrada desses sistemas lacustres.

Em 2014, Brandão et al. (2014) compararam as taxas de produção e eclosão de efípios de Daphnia laevis entre os períodos de estratificação térmica e de circulação na lagoa Jacaré, onde notaram uma diferença significativa na eclosão de efípios in situ e em laboratório para os dois períodos, sendo maior no de circulação da lagoa. Também, Maia-Barbosa et al. (2014) catalogaram a biodiversidade zooplanctônica e as características limnológicas de 18 lagoas, oito dentro da PERD e 10 em seu entorno, obtendo como resultados um total de 354 taxa, sendo que este ecossistema aquático apresenta mais da metade das espécies de zooplâncton já registradas para o estado de Minas Gerais, consistindo em uma das prioridades do Brasil. Ainda em 2014, Gonçalves et al. (2014) investigaram a dinâmica da matéria orgânica e o tipo de serrapilheira em uma área ribeirinha no domínio da Mata Atlântica em Timóteo, onde observaram que a dinâmica da queda das folhas na floresta de crescimento secundário foi fortemente influenciada pela chuva e pela elevação dos ventos fortes no final da estação seca, concluindo que a substituição e a redução de florestas primárias por monoculturas e/ou impactos antrópicos podem causar mudanças drásticas na zona ribeirinha.

$\mathrm{O}$ alto rio Doce apresenta-se como a região menos estudada, com apenas uma pesquisa desenvolvida antes do rompimento da barragem em Mariana - MG. Callisto et al. (2004) avaliaram a estrutura, diversidade e composição de grupos tróficos funcionais das comunidades de macroinvertebrados bentônicos, e caracterizaram a qualidade das águas nas 
Citação (APA): Carvalho, R. M., Gomes, V. A. P, Jankowsky, M., \& Freitas, R. R. (2021). Estudos ambientais da Bacia do Rio Doce no contexto pré e pós-rompimento da barragem de rejeitos de mineração. Brazilian Journal of Production Engineering, 6(8), Edição Especial "Pesca e Aquicultura: Gestão, Política e Inovação", 63-84.

cabeceiras da Bacia do Rio Doce. No total, 60 taxa de macroinvertebrados bentônicos foram identificados, sendo os insetos aquáticos o grupo dominante, e os rios estudados mostraram ser impróprios quanto à potabilidade, mas próprios para balneabilidade, em decorrência das altas contagens de bactérias heterotróficas e coliformes.

Em relação aos estudos que abrangem as três unidades regionais da bacia, dois trabalhos foram produzidos. No primeiro, Coelho (2009) traz uma análise socioambiental integrada da Bacia do Rio Doce, abordando as modificações promovidas pelas atividades impactantes nos aspectos gerais, em uma perspectiva histórica. No segundo, Jardim et al. (2014) avaliaram as florações de cianobactérias em diversificados pontos de amostras na bacia, onde associaram estatisticamente parâmetros ambientais e a qualidade da água, sendo possível verificar que: a temperatura da água variou nos meses mais frios dos anos, quando o Índice de Qualidade das Águas (IQA) se mostrou mais elevado; um ponto próximo ao esgoto tratado de uma lagoa de estabilização apresentou altas concentrações de fósforo, nitratos, oxigênio dissolvido, e redução do IQA; e as florações de cianobactérias em ecossistemas aquáticos lóticos do rio Doce foram coordenadas pelo regime hídrico, sendo muito mais densas na estação seca e fria.

Assim, as temáticas das pesquisas publicadas no período anterior ao rompimento da barragem compreendem: inventário do meio biótico, descrição de nova espécie, avaliação da qualidade ambiental com o uso de bioindicador e análise de comunidades em locais com diferentes usos e estados de conservação. As mesmas ocorrem nos artigos específicos de icitiofauna, com predomínio das descrições de novas espécies (Jankowsky et al., 2021). A partir desses estudos, fica nítido que a Bacia do Rio Doce nesse período apresentava um vasto meio biótico, o qual já era impactado pelas pressões das atividades antrópicas, com destaque para mineração, siderurgia, monoculturas, desmatamentos, poluição das águas por efluentes domésticos e industriais, caça e pesca ilegais, e introdução de espécies exóticas.

Ainda, constata-se que a região mais estudada compreende o médio rio Doce (18 artigos), com evidência para o PERD, salientando a importância desta área protegida para a pesquisa e a conservação da biodiversidade local. Em contrapartida, o baixo (três artigos) e o alto (um artigo) rio Doce apontam para uma ampla lacuna no conhecimento do meio biótico, bem como a carência de pesquisas que interconectem as três unidades regionais e promovam análises considerando a bacia hidrográfica como objeto de estudo, visto que somente dois artigos englobaram toda essa área. Essas mesmas constatações ocorrem nos trabalhos de ictiofauna, onde o médio rio Doce apresentou o maior número de estudos e, o baixo, o alto e a bacia hidrográfica apareceram com quantidade reduzida de publicações (Jankowsky et al., 2021).

\subsubsection{Publicações pós-rompimento da barragem de rejeitos de mineração}

No baixo rio Doce, 12 estudos foram desenvolvidos no período posterior ao desastre. Entre eles, na plataforma continental, Holz et al. (2020) identificaram algas coralinas que ocorrem como rodolitos, predominando em uma área de $1521 \mathrm{~km}^{2}$ de fundo do mar e sendo mais abundantes em profundidades entre 45 e 65 metros. Além disso, Assmar e Salles (2017) 
Citação (APA): Carvalho, R. M., Gomes, V. A. P, Jankowsky, M., \& Freitas, R. R. (2021). Estudos ambientais da Bacia do Rio Doce no contexto pré e pós-rompimento da barragem de rejeitos de mineração. Brazilian Journal of Production Engineering, 6(8), Edição Especial "Pesca e Aquicultura: Gestão, Política e Inovação", 63-84.

apresentaram os primeiros registros de Sisyridae no estado, expandindo o conhecimento da distribuição de cinco espécies de Climacia e Sisyra com coletas de indivíduos adultos.

Importantes discussões foram desenvolvidas a cerca da necessidade de esforços para monitorar e minimizar os possíveis impactos do rompimento da barragem na região do baixo rio Doce. Dentre elas, Miranda e Marques (2016) discorreram sobre o cnidário Kishinouyea corbini, a primeira espécie da classe Staurozoa registrada para o Brasil e com a única população conhecida localizada na Praia dos Padres, em Aracruz (ES), uma área impactada pela lama. Também, Costa et al. (2019) avaliaram os efeitos toxicológicos dos rejeitos em dois diferentes períodos de exposição sobre a fisiologia das algas Sargassum cymosum e Hypnea pseudomusciformis em cultura, ambas isoladas e em associação, demonstrando que a lama induziu danos fisiológicos e impactou sua interação ecofisiológica.

Avaliando os impactos significativos no estuário do rio Doce, Gomes et al. (2017) amostraram sedimentos para investigar os efeitos de curto prazo nas associações bentônicas e o acúmulo de traços de metal em sedimentos estuarinos, onde detectaram um predomínio de partículas de argila e aumento das concentrações de metal em até cinco vezes em algumas áreas, mudando significativamente a composição, diversidade e dominância trófica da macrofauna estuarina. A abordagem de eDNA metabarcoding foi utilizada por Bernardino et al. (2019) para avaliarem a biodiversidade bentônica no estuário 1,7 ano após os impactos iniciais do desastre, onde foram identificadas 123 novas variantes de sequência de taxa bentônicos e uma composição dominada por Nematoda, Crustacea e Platyhelminthes, apoiando a hipótese de impactos dos rejeitos nas assembleias estuarinas bentônicas, visto que as análises multivariadas revelaram forte influência de contaminação por ferro. Além disso, Fernandes et al. (2020) caracterizaram a comunidade zooplanctônica costeira após cinco dias dos rejeitos atingirem a foz do rio Doce, onde detectaram um impacto agudo nesta comunidade, com uma perda imediata de diversidade e um pico de abundância que foi caracterizado pelo domínio de poucas espécies oportunistas.

Tratando da biodisponibilidade de metais-traço na plataforma continental do rio Doce, Aguiar et al. (2020) amostraram sedimentos de fundo, algumas semanas antes do desastre e um ano e meio depois, onde apresentaram diferenças significativas nas concentrações, existindo um aumento desses metais no período posterior, com destaque para o chumbo. E sobre a análise da dispersão desses compostos, Marta-Almeida et al. (2016) acompanharam a pluma de rejeitos por dois meses após a chegada ao oceano, e os resultados indicaram grandes impactos, bem como revelaram que ela pode ter se dispersado centenas de quilômetros, com prevalência para o sul, atingindo regiões até a plataforma na cidade do Rio de Janeiro.

Pensando em impactos futuros, Magris et al. (2019) forneceram uma abordagem de modelagem para avaliar os efeitos nos principais ecossistemas e áreas marinhas protegidas. As simulações revelaram que a quantidade de sedimentos exportados pelo rio devido ao rompimento foi de até 180 vezes maior do que sem o impacto, as projeções de condições climáticas em um futuro próximo mostraram que as exportações de sedimentos podem permanecer elevadas e, as áreas de preocupação para conservação e com alta integridade biológica podem se tornar vulneráveis a distúrbios induzidos pelos sedimentos. Nesse 
Citação (APA): Carvalho, R. M., Gomes, V. A. P, Jankowsky, M., \& Freitas, R. R. (2021). Estudos ambientais da Bacia do Rio Doce no contexto pré e pós-rompimento da barragem de rejeitos de mineração. Brazilian Journal of Production Engineering, 6(8), Edição Especial "Pesca e Aquicultura: Gestão, Política e Inovação", 63-84.

contexto, Coimbra et al. (2020) avaliaram uma possível contaminação dos recifes de Abrolhos, durante e após a ruptura, e os resultados indicaram que apesar das concentrações mais elevadas de material particulado em suspensão terem sido restritas para a zona costeira e suas regiões mais rasas, sob circunstâncias excepcionais o vento soprou para o norte, em direção ao litoral nordestino brasileiro, e possivelmente até os recifes do Banco de Abrolhos. Dessa forma, Mazzei et al. (2016) evidenciam uma grande preocupação com esta região, dado que o Banco de Abrolhos no sul, próximo ao Espírito Santo, nunca foi reconhecido como uma prioridade de pesquisa, existindo grandes recifes ainda praticamente desconhecidos pela comunidade científica.

No médio Rio Doce, dois estudos foram desenvolvidos nesse período. Bezerra et al. (2017) avaliaram a presença da coerência temporal de variáveis limnológicas para três lagoas tropicais dentro do PERD - Carioca, Dom Helvécio, Gambazinho, e uma próxima ao parque Jacaré, demonstrando os maiores níveis de coerência temporal para temperatura da água, $\mathrm{pH}$ e carbono orgânico dissolvido, e os menores para clorofila-a e riqueza fitoplanctônica. No âmbito do desastre, Espindola et al. (2016) contextualizaram historicamente o rompimento e seus desafios para a conservação da biodiversidade, onde destacaram que os efeitos da pluma de rejeitos no Rio Doce puderam ser percebidos no PERD, sendo esta a maior área contínua de Mata Atlântica do estado de Minas Gerais e o terceiro maior sistema lacustre do Brasil. Dentre os impactos mais visíveis observaram a mortandade no meio biótico, além da entrada da lama nos ribeirões que deságuam no rio Doce, impactando a fauna desses afluentes.

No alto Rio Doce foram desenvolvidas 7 pesquisas. Dentre elas, Knopff et al. (2020) apresentaram como as etapas da avaliação de impacto na biodiversidade foram abordadas no pós-desastre nessa região, visto que, os dados da linha de base anterior ao desastre eram escassos, e pouco se sabia a respeito de como as vias de impacto relacionadas ao rompimento poderiam ter afetado a biodiversidade terrestre. A reconstrução da linha de base revelou que aproximadamente 1580 ha de ecossistemas terrestres foram suprimidos, incluindo 480 ha de Mata Atlântica, e foram identificadas 346 espécies de vertebrados, invertebrados e plantas vasculares ameaçadas de extinção ocorrentes ou potencialmente ocorrentes nas áreas afetadas, bem como nove vias de impactos.

Ainda, Omachi et al. (2018) estimaram a região florestada inundada pelos rejeitos de minério, identificando a perda de 457,6 ha de área florestal, a qual se concentrava nos primeiros $74 \mathrm{~km}$ da barragem de Fundão. Em Barra Longa - MG, o segundo município atingido pelo desastre, Cruz et al. (2020) avaliaram os efeitos dos rejeitos sobre a germinação e crescimento inicial de espécies arbóreas nativas da Mata Atlântica, demonstrando uma interferência negativa no crescimento das plantas devido às limitações nutricionais por baixo teor de nutrientes disponível, baixo teor de matéria orgânica e baixa capacidade de troca catiônica dos rejeitos.

Abordando métodos para mitigar os impactos dos rejeitos, Zago et al. (2019) analisaram os efeitos na flora e sua remediação, avaliando o desenvolvimento, a produção de biomassa e a absorção de elementos minerais tóxicos em três espécies de gramíneas aromáticas, onde identificou-se que o fitomanejo pode ter uma contribuição significativa para a recuperação gradual da área afetada. Também, Aires et al. (2018) aplicaram uma análise multicritério para 

"Pesca e Aquicultura: Gestão, Política e Inovação", 63-84.

a definição de áreas potenciais de destinação dos rejeitos decorrentes do rompimento, os quais se acumularam nas margens dos rios nos municípios de Mariana e Barra Longa. O maior local identificado na análise para o município de Mariana apresentou tamanho de $0,25 \mathrm{~km}^{2}$, enquanto no município de Barra Longa o maior sítio identificada tem um tamanho de 0,037 $\mathrm{km}^{2}$, com um valor de adequação maior.

No rio Gualaxo do Norte, primeiro corpo hídrico atingido após o desastre, Batista et al. (2020) avaliaram as características mais afetadas relacionadas à ecofisiologia e atividade microbiana, e investigaram suas relações com os condutores ambientais nos rejeitos. O estudo sugere que as propriedades físico-químicas e até mesmo a presença de baixas concentrações biodisponíveis de metais pesados nos rejeitos promovem mudanças nas comunidades microbianas e na ciclagem biogeoquímica de nutrientes, demonstrando implicações negativas para o funcionamento dos ecossistemas. Além disso, na Bacia Hidrográfica do Rio do Peixe, importante afluente do rio Doce, Nascimento et al. (2019) avaliaram as possíveis relações de interferência antrópica na qualidade das águas superficiais, onde as variáveis de maior influência foram E. coli, DBO, turbidez, nitrato e fósforo total, indicando que os principais impactos ambientais dessa bacia incluem desmatamento, erosão, esgoto doméstico e os rejeitos de minério de ferro.

Em relação aos estudos que abrangem as três unidades regionais, 13 trabalhos foram produzidos. Visto que a Bacia do Rio Doce está inserida no bioma Mata Atlântica e apresenta uma paisagem bastante fragmentada, cinco estudos trataram do contexto florestal dessa região. Carvalho et al. (2020) mapearam a Vocação de Restauração Florestal (FRV), onde mostraram que $44 \%$ das áreas antropizadas apresentam favorabilidade média a alta para restauração passiva (regeneração natural assistida), enquanto 4,3 Mha estão profundamente degradados, requerendo florestamento por meio de restauração ativa. Pires et al. (2017) examinaram a conformidade do Novo Código Florestal na bacia, e descobriram que o cumprimento da legislação exigiria a restauração de cerca de 716 mil hectares de floresta ribeirinha em toda a bacia, e o aumento das áreas florestadas melhoraria a resistência e resiliência à queda de água durante as estações chuvosa e seca, respectivamente, bem como a qualidade da água e a remoção de $\mathrm{CO}_{2}$ da atmosfera, com uma viabilidade financeira alcançável. Silveira et al. (2019a; 2019b) abordaram os estoques de carbono terrestre e biomassa acima do solo (AGB), onde estimaram um total de 178.967.656,73 Mg de AGB, bem como destacaram o aumentando da precisão das estimativas com a abordagem baseada em objetos. E Lyra e Rigo (2019) analisaram, através de modelagens, as consequências do desmatamento no comportamento hidrológico da bacia, onde constataram que a substituição de florestas por pastagens provoca reduções nas vazões médias anuais, o desmatamento promove o aumento das cheias, e a retirada das florestas intensifica os problemas já encontrados nessa bacia, como inundações e escassez de água para suprimento dos usos para os quais ela se destina.

Ademais, cinco pesquisas realizaram avaliações de impactos ambientais promovidos pelo desastre. Hatje et al. (2017) analisaram o derramamento de rejeito de ferro ao longo de mais de $650 \mathrm{~km}$, e como resultados, observaram que ele causou um aumento substancial nas cargas 
Citação (APA): Carvalho, R. M., Gomes, V. A. P, Jankowsky, M., \& Freitas, R. R. (2021). Estudos ambientais da Bacia do Rio Doce no contexto pré e pós-rompimento da barragem de rejeitos de mineração. Brazilian Journal of Production Engineering, 6(8), Edição Especial "Pesca e Aquicultura: Gestão, Política e Inovação", 63-84.

de sedimentos suspensos, e o transporte de metais dissolvidos estimado mais alto foi observado para Fe, Ba e Al. Santos et al. (2019) também realizaram uma avaliação abrangente dos impactos ambientais, onde constataram: a deposição de sedimentos no rio transformando a morfologia de um perfil sinuoso para um aspecto trançado; o esgotamento do conteúdo de nutrientes, minerais e matéria orgânica do solo, enquanto $\mathrm{NH}_{4}{ }^{+}, \mathrm{Na}$ e o $\mathrm{pH}$ aumentaram; a eliminação da biomassa microbiana total nos sedimentos em relação a solos de locais preservados; e a mortalidade geral das plantas, bem como uma baixa capacidade de resiliência. Em 18 áreas da bacia, Buch et al. (2020) avaliaram a toxicidade dos rejeitos de Fundão para ácaros oribatídeos do solo, onde as percentagens de sobrevivência do ácaro e a inibição reprodutiva foram maiores em $60 \%$ e $80 \%$, respectivamente, em todas as áreas contaminadas. Além disso, Quadra et al. (2019) investigaram as concentrações de oligoelementos e os efeitos citogenotóxicos dos rejeitos liberados pelo rompimento da barragem de Fundão, onde observaram concentrações extremamente altas de partículas de Fe, Al e Mn nos locais impactados, e efeitos citogenotóxicos, como alterações nos índices mitóticos e aumento da frequência de aberrações cromossômicas. E Cordeiro et al. (2019) hipotetizaram de forma plausível que os rejeitos de minério mudaram a diversidade e atividade microbiana no rio Doce, e usando metagenômica para identificar as alterações nos tipos e no metabolismo microbiano relacionado ao depósito de rejeitos, demonstraram efeitos de curto prazo, como genes relacionados ao ciclo do ferro e resistência aos metais, evidenciando que o rio Doce ainda não tinha se estabilizado um ano após o desastre.

Sobre a história e o contexto atual da bacia, três estudos trouxeram discussões muito relevantes. Felippe et al. (2016) salientaram que a Bacia do Rio Doce se configura como um mosaico complexo de paisagens, uma herança dos processos geo-históricos de ocupação e exploração econômica e ambiental, onde sua porção leste reflete de modo mais evidente as mazelas do histórico processo de desmatamento, enquanto o oeste vive o constante risco das atividades de mineração. Nesse contexto, Meira-Neto e Neri (2017) afirmaram que o maior impacto ambiental já registrado nessa bacia ocorreu com o rompimento da barragem de rejeitos de Fundão, e incitaram uma enorme preocupação, dado que muito sobre a biodiversidade da região permanece desconhecida, e ainda se aguarda o apoio efetivo para o desenvolvimento de projetos que amenizem esse desastre, os quais precisam ser coordenados de forma conjunta por governos, empresas, instituições tecnológicas e universidades, tronando-se necessário o avanço na produção de ferramentas científicas e tecnológicas para o seu enfrentamento. Pinheiro et al. (2019) incrementaram essa inquietação, apontando que o ocorrido em Mariana não deve ser visto como um caso isolado, uma vez que até o momento nada foi feito para evitar novos acontecimentos como este no futuro, mesmo com o conhecimento de outras 350 barragens de mineração em Minas Gerais estarem com suas estruturas comprometidas, com alto risco de rompimento.

Assim, as temáticas das pesquisas publicadas no período posterior ao rompimento da barragem compreendem: inventário do meio biótico, descrição de nova espécie, contexto florestal da bacia, avaliação dos impactos dos rejeitos de mineração, projeção dos impactos futuros promovidos pela lama, avaliação de métodos para mitigação dos efeitos do rompimento e história dos impactos da bacia com ênfase no cenário atual. Os mesmos temas 
Citação (APA): Carvalho, R. M., Gomes, V. A. P, Jankowsky, M., \& Freitas, R. R. (2021). Estudos ambientais da Bacia do Rio Doce no contexto pré e pós-rompimento da barragem de rejeitos de mineração. Brazilian Journal of Production Engineering, 6(8), Edição Especial "Pesca e Aquicultura: Gestão, Política e Inovação", 63-84.

são abordados nos artigos específicos de ictiofauna, com predomínio dos estudos de avaliação dos impactos nos peixes devido à contaminação promovida pelo desastre (Jankowsky et al., 2021). A partir desses trabalhos, entende-se que a Bacia do Rio Doce passou por modificação do seu meio biótico, o qual ainda se apresenta pouco conhecido, e que a somatória dos impactos das atividades antrópicas já existentes com os enormes efeitos promovidos pelo rompimento da barragem, tornou toda a conjuntura ambiental da bacia altamente vulnerável.

Ainda, constata-se que o número total de artigos do meio biótico aumentou após o desastre, sendo que as regiões mais estudadas compreendem a bacia hidrográfica como um todo (13 artigos) e o baixo Rio Doce (12 artigos). Em contrapartida, o médio (2 artigos) e o alto (sete artigos) apontam para maiores lacunas no conhecimento da biodiversidade e de suas condições a partir dos novos desafios impostos pelo ocorrido. Para os trabalhos específicos de ictiofauna, o número de artigos publicados diminuiu após o desastre, onde o baixo rio Doce apresentou o maior número de estudos e o médio apareceu com quantidade reduzida de publicações (Jankowsky et al., 2021).

\section{CONSIDERAÇÕES FINAIS}

A partir da análise bibliométrica de todos os estudos obtidos com a procura dos termos de busca nas bases de dados, fica explícito o grande aumento do número de artigos publicados após o rompimento da barragem de Fundão, onde em menos de cinco anos foram produzidos quase $2 / 3$ dos trabalhos relacionados à atividade pesqueira da Bacia do Rio Doce. Além disso, constata-se um maior interesse da comunidade científica internacional em estudar a região, dada a ampliação da área de abrangência das publicações nesse período, segundo o enfoque das bases de dados. Também, observa-se uma visão mais aprofundada do cenário da bacia nos últimos dois anos, o que reflete uma melhor percepção das fortalezas, oportunidades, fraquezas e ameaças da região.

Com a análise dos estudos ambientais relacionados especificamente ao meio biótico, fica nítida a mudança das temáticas das pesquisas e das lacunas de conhecimento nos períodos pré e pós-rompimento da barragem. No período anterior, notam-se estudos voltados para o conhecimento da biodiversidade local, bem como da qualidade do meio no qual ela se insere, demonstrando que os aspectos ambientais da bacia já se apresentavam impactados pelas atividades antrópicas, apesar da importância ambiental da região. Em contrapartida, no momento posterior, a maior parte dos estudos volta-se para a avaliação de impacto dos rejeitos de mineração, analisando as comunidades e o seu entorno após a chegada da lama. Ainda, atenta-se para o número de estudos em cada unidade regional da bacia, onde no prérompimento a região mais estudada compreende o médio rio doce, com destaque para a área protegida do Parque Estadual do Rio Doce, e a menos conhecida consiste na unidade regional do alto. Após o rompimento, esse cenário se transforma, onde a bacia passa a ser o maior objeto de estudo, e a região do médio torna-se a menos estudada.

Portanto, a partir do conhecimento científico analisado conclui-se que a Bacia Hidrográfica do Rio Doce compreende uma área altamente impactada pelas atividades antrópicas, e o rompimento da barragem de Fundão, que se apresenta como um dos maiores desastres 
ambientais registrado no país, intensificou enormemente os efeitos no meio biótico local, o qual apresentou drásticas modificações em suas comunidades. Apesar do aumento das pesquisas nessa região nos últimos anos, aponta-se a necessidade da intensificação dos estudos na bacia, dada sua importância para o meio socioambiental, visando uma gestão mais sustentável dos recursos naturais.

\section{AgRAdECIMENTO/ FinANCIAMENTO}

O presente trabalho foi realizado com o financiamento da Fundação Renova, como parte do cumprimento do Termo de Transação de Ajustamento de Conduta (TTAC), através do Projeto de Monitoramento e Caracterização Socioeconômica da Atividade Pesqueira no Rio Doce e Litoral do Espírito Santo, contrato número 8600002299, desenvolvido pelo Instituto de Pesca e Universidade Federal do Espírito Santo.

\section{REFERÊNCIAS BIBLIOGRÁFICAS}

Aguiar, V. M. de C., Neto, J. A. B., Quaresma, V. da S., Bastos, A. C., \& Athayde, J. P. M. de. (2020). Bioavailability and ecological risks of trace metals in bottom sediments from Doce river continental shelf before and after the biggest environmental disaster in Brazil: The collapse of the Fundão dam. Journal of Environmental Management, 272 (May). https://doi.org/10.1016/j.jenvman.2020.111086.

Aires, U. R. V., Santos, B. S. M., Coelho, C. D., da Silva, D. D., \& Calijuri, M. L. (2018). Changes in land use and land cover as a result of the failure of a mining tailings dam in Mariana, MG, Brazil. Land Use Policy, 70 (September 2017), 63-70. https://doi.org/10.1016/j.landusepol.2017.10.026.

Assmar, A. C., \& Salles, F. F. (2017). Taxonomic and distributional notes on Spongilla-flies (Neuroptera: Sisyridae) from Southeastern Brazil with first interactive key to the species of the country. Zootaxa, 4273(1), 80-92. https://doi.org/10.11646/zootaxa.4273.1.6.

Barros, C. F. de A., dos Santos, A. M. M., \& Barbosa, F. A. R. (2013). Phytoplankton diversity in the middle rio Doce lake system of southeastern brazil. Acta Botanica Brasilica, 27(2), 327-346. https://doi.org/10.1590/S0102-33062013000200009.

Batista, É. R., Carneiro, J. J., Araújo Pinto, F., dos Santos, J. V., \& Carneiro, M. A. C. (2020). Environmental drivers of shifts on microbial traits in sites disturbed by a large-scale tailing dam collapse. Science of the Total Environment, 738, 139453. https://doi.org/10.1016/j.scitotenv.2020.139453.

Bartolini, M., Bottani, E., \& Eric, H. (2019). Green warehousing: Systematic literature review and bibliometric analysis. Journal of Cleaner Production, 226, 242-258.

Behling, H., Arz, H. W., Patzold, J., \& Wefer, G. (2002). Late Quaternary vegetational and climate dynamics in southeastern Brazil, inferences from marine cores GeoB 3229-2 and GeoB 3202-1. Palaeogeography, Palaeoclimatology, Palaeoecology, 179, 227-243.

Berkes, F., Colding, J., \& Folke, C. (Eds.) (2003). Navigating Social-Ecological Systems: Building Resilience for Complexity and Change. Cambridge University Press, Cambridge, UK. 410p. 
Citação (APA): Carvalho, R. M., Gomes, V. A. P, Jankowsky, M., \& Freitas, R. R. (2021). Estudos ambientais da Bacia do Rio Doce no contexto pré e pós-rompimento da barragem de rejeitos de mineração. Brazilian Journal of Production Engineering, 6(8), Edição Especial "Pesca e Aquicultura: Gestão, Política e Inovação", 63-84.

Bernardino, A. F., Pais, F. S., Oliveira, L. S., Gabriel, F. A., Ferreira, T. O., Queiroz, H. M., \& Mazzuco, A. C. A. (2019). Chronic trace metals effects of mine tailings on estuarine assemblages revealed by environmental DNA. PeerJ Preprints, 7. https://doi.org/10.7717/peerj.8042.

Bezerra, M. P., Barbosa, P. M., Barbosa, F. A. R., \& Bezerra Neto, J. F. (2017). Temporal coherence of physical, chemical and biological variables in four tropical lakes (Minas Gerais, Brazil). Acta Limnologica Brasiliensia, 29(0). https://doi.org/10.1590/s2179-975x6716.

Brandão, L., Fajardo, T., Eskinazi-Sant'Anna, E., Brito, S., \& Maia-Barbosa, P. (2012). Fluctuations of the population of Daphnia laevis Birge 1878: a six-year study in a tropical lake. Brazilian Journal of Biology, 72(3), 479-487. https://doi.org/10.1590/s151969842012000300010.

Brandão, L., Pujoni, D., \& Maia-Barbosa, P. (2014). Seasonal dynamics of Daphnia laevisBirge, 1878 ephippia in a tropical lake with a description of a new methodology for in situ evaluation. Brazilian Journal of Biology, 74(3), 642-648. https://doi.org/10.1590/bjb.2014.0069.

Buch, A. C., Sautter, K. D., Marques, E. D., \& Silva-Filho, E. V. (2020). Ecotoxicological assessment after the world's largest tailing dam collapse (Fundão dam, Mariana, Brazil): effects on oribatid mites. Environmental Geochemistry and Health, 4. https://doi.org/10.1007/s10653-020-00593-4.

Callisto, M., Goulart, M., Medeiros, A. O., Moreno, P., \& Rosa, C. A. (2004). Diversity assessment of benthic macroinvertebrates, yeasts, and microbiological indicators along a longitudinal gradient in Serra do Cipó, Brazil. Brazilian Journal of Biology = Revista Brasleira de Biologia, 64(4), 743-755. https://doi.org/10.1590/s1519-69842004000500003.

Carvalho, S. M. R., Rajão, R., Nunes, F., Assis, D., Neto, J. A., Marcolino, C., Lima, L., Rickard, T., Salomão, C., \& Filho, B. S. (2020). A spatially explicit index for mapping Forest Restoration Vocation (FRV) at the landscape scale: Application in the Rio Doce basin, Brazil. Science of The Total Environment. https://doi.org/10.1016/j.scitotenv.2020.140647.

Cavati, B., \& Fernandes, V. de O. (2008). Algas perifíticas em dois ambientes do baixo rio Doce (lagoa Juparanã e rio Pequeno - Linhares, Estado do Espírito Santo, Brasil): Variação espacial e temporal. Acta Scientiarum - Biological Sciences, 30(4), 439-448. https://doi.org/10.4025/actascibiolsci.v30i4.535.

Coelho, A. L. N. (2009). Bacia hidrográfica do Rio Doce (MG/ES): uma análise socioambiental integrada. Revista Geografares, 7, 131-146. https://doi.org/10.7147/geo7.156.

Coimbra, K. T. O., Alcântara, E., \& Filho, C. R. S. (2020). Possible contamination of the Abrolhos reefs by Fundao dam tailings, Brazil - New constraints based on satellite data. Science of the Total Environment, 733 (November 2015), 138101. https://doi.org/10.1016/j.scitotenv.2020.138101.

Colombi, V. H., Lopes, S. R., \& Fagundes, V. (2010). Testing the Rio Doce as a riverine barrier in shaping the atlantic rainforest population divergence in the rodent Akodon cursor. Genetics and Molecular Biology, 33(4), 785-789. https://doi.org/10.1590/S141547572010000400029.

Cordeiro, M. C., Garcia, G. D., Rocha, A. M., Tschoeke, D. A., Campeão, M. E., Appolinario, L. R., Soares, A. C., Leomil, L., Froes, A., Bahiense, L., Rezende, C. E., de Almeida, M. G., Rangel, T. P., De Oliveira, B. C. V., de Almeida, D. Q. R., Thompson, M. C., Thompson, C. 
Citação (APA): Carvalho, R. M., Gomes, V. A. P, Jankowsky, M., \& Freitas, R. R. (2021). Estudos ambientais da Bacia do Rio Doce no contexto pré e pós-rompimento da barragem de rejeitos de mineração. Brazilian Journal of Production Engineering, 6(8), Edição Especial "Pesca e Aquicultura: Gestão, Política e Inovação", 63-84.

C., \& Thompson, F. L. (2019). Insights on the freshwater microbiomes metabolic changes associated with the world's largest mining disaster. Science of the Total Environment, 654. https://doi.org/10.1016/j.scitotenv.2018.11.112.

Costa, G. B., Ramlov, F., de Ramos, B., Koerich, G., Gouvea, L., Costa, P. G., Bianchini, A., Maraschin, M., \& Horta, P. A. (2019). Physiological damages of Sargassum cymosum and Hypnea pseudomusciformis exposed to trace metals from mining tailing. Environmental Science and Pollution Research, 26(36), 36486-36498. https://doi.org/10.1007/s11356-01906691-w.

Cruz, F. V. da S., Gomes, M. P., Bicalho, E. M., Della Torre, F., \& Garcia, Q. S. (2020). Does Samarco's spilled mud impair the growth of native trees of the Atlantic Rainforest? Ecotoxicology and Environmental Safety, 189, 110021.

Dupont, W. D., Plummer, W. D. (1990). Power and sample size calculations. Controlled Clinical Trials, 11(2), 116-128.

Espindola, H. S., Campos, R. B. F., Lamounier, K. C. C., \& Silva, R. S. (2016). Desastre da Samarco no Brasil: Desafios para a conservação da biodiversidade. Fronteiras, 5(3), 72-100. https://doi.org/10.21664/2238-8869.2016v5i3.p72-100.

Felippe, M. F., Junior, A. P. M., Mendes, L. C., Cota, G. E. M., Carneiro, P. S., \& Gontijo, B. M. (2016). Conexões geo-históricas e contemporâneas entre ocupação territorial, degradação ambiental e rarefação hídrica na Bacia do Rio Doce. Geografias, 203-222.

Fernandes, L. F. L., Paiva, T. R. M., Longhini, C. M., Pereira, J. B., Ghisolfi, R. D., Lázaro, G. C. S., Demoner, L. E., Laino, P. de S., Conceição, L. R. da, Sá, F., Neto, R. R., Dias Junior, C., Lemos, K. do N., Quaresma, V. da S., Oliveira, K. S., Grilo, C. F., \& Rocha, G. M. (2020). Marine zooplankton dynamics after a major mining dam rupture in the Doce River, southeastern Brazil: Rapid response to a changing environment. Science of the Total Environment, 736. https://doi.org/10.1016/j.scitotenv.2020.139621.

Ferreira, F. A., Mormul, R. P., Pedralli, G., Pott, V. J., \& Pott, A. (2010). Estrutura da comunidade de macrófitas aquáticas em três lagoas do Parque Estadual do Rio Doce, Minas Gerais, Brasil. Hoehnea, 37(1), 43-52. https://doi.org/10.1590/s2236-89062010000100003.

França, M. C., Cohen, M. C. L., Pessenda, L. C. R., Rossetti, D. F., Lorente, F. L., Buso Junior, A. Á., Guimarães, J. T. F., Friaes, Y., \& Macario, K. (2013). Mangrove vegetation changes on Holocene terraces of the Doce River, southeastern Brazil. Catena, 110, 59-69. https://doi.org/10.1016/j.catena.2013.06.011.

França, M.C., Alves, I. C. C., Cohen, M. C. L., Rossetti, D. F., Pessenda, L. C. R., Giannini, P. C. F., Lorente, F. L., Buso Junior, A. Á., Bendassolli, J. A., \& Macario, K. (2016). Millennial to secular time-scale impacts of climate and sea-level changes on mangroves from the Doce River delta, Southeastern Brazil. Holocene, 26(11), 1733-1749. https://doi.org/10.1177/0959683616645938.

Gomes, L. E. O., Correa, L. B., Sá, F., Neto, R. R., \& Bernardino, A. F. (2017). The impacts of the Samarco mine tailing spill on the Rio Doce estuary, Eastern Brazil. Marine Pollution Bulletin, 120(1-2), 28-36. https://doi.org/10.1016/j.marpolbul.2017.04.056.

Gonçalves, J. F., de Souza Rezende, R., Gregório, R. S., \& Valentin, G. C. (2014). Relationship between dynamics of litterfall and riparian plant species in a tropical stream. Limnologica, 44, 40-48. https://doi.org/10.1016/j.limno.2013.05.010. 
Citação (APA): Carvalho, R. M., Gomes, V. A. P, Jankowsky, M., \& Freitas, R. R. (2021). Estudos ambientais da Bacia do Rio Doce no contexto pré e pós-rompimento da barragem de rejeitos de mineração. Brazilian Journal of Production Engineering, 6(8), Edição Especial "Pesca e Aquicultura: Gestão, Política e Inovação", 63-84.

Hatje, V., P, R. M. A., De Rezende, C. E., S, C. A. F., S, G. C., M, D. C., \& Hackspacher, P. C. (2017). The environmental impacts of one of the largest tailing dam failures worldwide. Scientific Reports, 7(1). https://doi.org/10.1038/s41598-017-11143-X.

Holz, L., Bahia, R. G., Karez, S., Vieira, F. V, Moraes, F. C., Vale, N. F., Sudatti, D. B., Salgado, L. T., Moura, R. L., Amado-filho, G. M., \& Bastos, A. C. (2020). Structure of Rhodolith Beds and Surrounding Habitats at the Doce River Shelf (Brazil). Diversity, 12(75), 1-19.

Hu, J., Ma, Y., Zhang, L., Gan, F., Ho, Y. S. (2010). A historical review and bibliometric analysis of research on lead in drinking water field from 1991 to 2007. Science of the Total Environment, 408, 1738-1744. https://doi:10.1016/j.scitotenv.2009.12.038.

Jardim, F. A., von Sperling, E., Jardim, B. F. de M., \& Almeida, K. C. de B. (2014). Fatores determinantes das florações de cianobactérias na água do Rio Doce, Minas Gerais, Brasil. Engenharia Sanitária e Ambiental, 19(3), 207-218. https://doi.org/10.1590/S141341522014019000001026.

Jankowsky, M., Carvalho, R. M., Gomes, V. A. P, \& Freitas, R. R. (2021). Peixes e pesca na Bacia do Rio Doce, uma análise bibliométrica. Brazilian Journal of Production Engineering, 6(8), 14-40. https://doi.org/10.47456/bjpe.v6i8.33769.

Knopff, K., Bede, L. C., Arruda, L., Alves, T., \& Simons, B. (2020). Methods for PostDisaster Impact Assessment: A Case Study of the Impacts of the Fundão Dam Failure on Terrestrial Species Threatened with Extinction. Integrated Environmental Assessment and Management, 00(00), 1-5. https://doi.org/10.1002/ieam.4265.

Lima, A. T., Bastos, F. A., Teubner, F. J., Neto, R. R., Cooper, A., \& Barroso, G. F. (2020). Strengths and Weaknesses of a Hybrid Post-disaster Management Approach: the Doce River (Brazil) Mine-Tailing Dam Burst. Environmental Management, 65(6), 711-724. Retrieved from http://link.springer.com/10.1007/s00267-020-01279-4.

Lyra, B. U., \& Rigo, D. (2019). Deforestation impact on discharge regime in the Doce River Basin. Revista Ambiente e Água, 14(4). https://doi.org/doi:10.4136/ambi-agua.2370.

Magris, R. A., Marta-Almeida, M., Monteiro, J. A. F., \& Ban, N. C. (2019). A modelling approach to assess the impact of land mining on marine biodiversity: Assessment in coastal catchments experiencing catastrophic events (SW Brazil). Science of the Total Environment, 659. https://doi.org/10.1016/j.scitotenv.2018.12.238.

Maia-Barbosa, P. M., Menendez, R. M., Pujoni, D. G. F., Brito, S. L., Aoki, a., \& Barbosa, F. a. R. (2014). Zooplankton (Copepoda, Rotifera, Cladocera and Protozoa: Amoeba Testacea) from natural lakes of the middle Rio Doce basin, Minas Gerais, Brazil. Biota Neotropica, 14(1), 1-20.

Marques, M. M., Barbosa, F. A., \& Callisto, M. (1999a). Distribution and abundance of chironomidae (Diptera, Insecta) in an impacted watershed in south-east Brazil. Revista Brasileira de Biologia, 59(4), 553-561. https://doi.org/10.1590/S0034-71081999000400004.

Marques, M. G. S. M., Ferreira, R. L., \& Barbosa, F. A. R. (1999b). A comunidade de macroinvertebrados aquáticos e características limnológicas das lagoas Carioca e da Barra, Parque Estadual do Rio Doce, MG. Revista Brasileira de Biologia, 59(2), 203-210. https://doi.org/10.1590/s0034-71081999000200004. 
Citação (APA): Carvalho, R. M., Gomes, V. A. P, Jankowsky, M., \& Freitas, R. R. (2021). Estudos ambientais da Bacia do Rio Doce no contexto pré e pós-rompimento da barragem de rejeitos de mineração. Brazilian Journal of Production Engineering, 6(8), Edição Especial "Pesca e Aquicultura: Gestão, Política e Inovação", 63-84.

Marques, M. M., \& Barbosa, F. (2001). Biological quality of waters from an impacted tropical watershed (middle Rio Doce basin, southeast Brazil), using benthic macroinvertebrate communities as an indicator. Hydrobiologia, 457, 69-76. https://doi.org/10.1023/A:1012297915323.

Marta-Almeida, M., Mendes, R., Amorim, F. N., Cirano, M., \& Dias, J. M. (2016). Fundão Dam collapse: Oceanic dispersion of River Doce after the greatest Brazilian environmental accident. Marine Pollution Bulletin, 112, 359-364.

Mayorga, L. F. S. P., Vanstreels, R. E. T., Bhering, R. C. C., Mamede, N., Costa, L. M. B., Pinheiro, F. C. F., Reis, L. W. D., Trazzi, A., Meirelles, W. L. C., Ribeiro, A. M., \& Siciliano, S. (2020). Strandings of cetaceans on the Espírito Santo Coast, Southeast Brazil, 1975-2015. ZooKeys, 2020(948), 129-152. https://doi.org/10.3897/zookeys.948.50468.

Mazzei, E. F., Bertoncini, A. A., Pinheiro, H. T., Machado, L. F., Vilar, C. C., Guabiroba, H. C., Costa, T. J. F., Bueno, L. S., Santos, L. N., Francini-Filho, R. B., Hostim-Silva, M., \& Joyeux, J. C. (2016). Newly discovered reefs in the southern Abrolhos Bank, Brazil: Anthropogenic impacts and urgent conservation needs. Marine Pollution Bulletin, 114(1), 123-133. https://doi.org/10.1016/j.marpolbul.2016.08.059.

Medeiros, A. O., Kohler, L. M., Hamdan, J. S., Missagia, B. S., Barbosa, F. A. R., \& Rosa, C. A. (2008). Diversity and antifungal susceptibility of yeasts from tropical freshwater environments in Southeastern Brazil. Water Research, 42(14), 3921-3929. https://doi.org/10.1016/j.watres.2008.05.026.

Medeiros, A. O., Missagia, B. S., Brandão, L. R., Callisto, M., Barbosa, F. A. R., \& Rosa, C. A. (2012). Water quality and diversity of yeasts from tropical lakes and rivers from the Rio Doce basin in Southeastern Brazil. Brazilian Journal of Microbiology, 43(4), 1582-1594. https://doi.org/10.1590/S1517-83822012000400043.

Meira-Neto, J. A. A., \& Neri, A. V. (2017). Appealing the death sentences of the Doce, São Francisco and Amazonas rivers: stopping the Mining Lobby and creating ecosystem services reserves. Perspectives in Ecology and Conservation, 15(3), 199-201. https://doi.org/10.1016/j.pecon.2017.06.008.

Miranda, F. S., Pinto-Coelho, R. M., \& Gonzaga, A. V. (2013). Redução da riqueza de organismos do zooplâncton (com ênfase em Copepoda e Cladocera) nas lagoas do médio Rio Doce/MG. Revista Brasileira de Zoociências, 15(1, 2, 3), 69-90.

Miranda, L. S., \& Marques, A. C. (2016). Hidden impacts of the Samarco mining waste dam collapse to Brazilian marine fauna - an example from the staurozoans (Cnidaria). Biota Neotropica, 16(2), 1-4. https://doi.org/10.1590/1676-0611-bn-2016-0169.

Mishra, D., Gunasekaran, A., Papadopoulos, T., \& Childe, S. J. (2016). Big Data and supply chain management: a review and bibliometric analysis. Annals of Operations Research, 270(1-2), 313-336. https://doi.org/10.1007/s10479-016-2236-y.

Morais, M. M., Miranda, R. F., Barroso-silva, K., \& Latini, A. O. (2012). Evaluating water resource maintenance for lakes of the middle Doce river. Acta Scientiarum. Biological Sciences, 34(3), 297-301. https://doi.org/10.4025/actascibiolsci.v34i3.8703.

Nascimento, L. P. do, Reis, D. A., Roeser, H. M. P., \& Santiago, A. da F. (2019). Relationship between land use and water quality in a watershed impacted by iron ore tailings and domestic sewage. Revista Ambiente e Agua, 14(5). https://doi.org/10.4136/ambiagua.2383. 
Omachi, C. Y., Siani, S. M. O., Chagas, F. M., Mascagni, M. L., Cordeiro, M., Garcia, G. D., Thompson, C. C., Siegle, E., \& Thompson, F. L. (2018). Atlantic Forest loss caused by the world's largest tailing dam collapse (Fundão Dam, Mariana, Brazil). Remote Sensing $\begin{array}{llll}\text { Applications: } \quad \text { Society } & \text { and }\end{array}$ https://doi.org/10.1016/j.rsase.2018.08.003.

Peixoto, R. S., Brandão, L. P. M., Valadares, C. de F., \& Barbosa, P. M. M. (2010). Occurrence of Kellicottia bostoniensis (Rousselet, 1908) and Mesocyclops ogunnus Onabamiro, 1957 in lakes of the Middle River Doce, MG, Brazil. Acta Limnologica Brasiliensia, 22(3), 356-360. https://doi.org/10.4322/actalb.02203012.

Petrucio, M. M., \& Barbosa, F. A. R. (2004). Diel variations of phytoplankton and bacterioplankton production rates in four tropical lakes in the middle Rio Doce basin $\begin{array}{llll}\text { (southeastern } \quad \text { Brazil). } & \text { Hydrobiologia, } & \text { 513, }\end{array}$ https://doi.org/10.1023/B:hydr.0000018167.43745.33.

Petrucio, Mauricio M., Barbosa, F. A. R., \& Furtado, A. L. S. (2006). Bacterioplankton and phytoplankton production in seven lakes in the Middle Rio Doce basin, south-east Brazil. Limnologica, 36(3), 192-203. https://doi.org/10.1016/j.limno.2006.05.001.

Pinheiro, H. T., Teixeira, J. B., Francini-Filho, R. B., Soares-Gomes, A., Ferreira, C. E. L., \& Rocha, L. A. (2019). Hope and doubt for the world's marine ecosystems. Perspectives in Ecology and Conservation, 17(1), 19-25. https://doi.org/10.1016/j.pecon.2018.11.001.

Pires, A. P. F., Rezende, C. L., Assad, E. D., Loyola, R., \& Scarano, F. R. (2017). Forest restoration can increase the Rio Doce watershed resilience. Perspectives in Ecology and Conservation, 15(3), 187-193. https://doi.org/10.1016/j.pecon.2017.08.003.

Pitelli, R. L. C. M., Pitelli-Merenda, A. M. C. M., Pitelli, R. A., Siqueira, R. C., Barbosa, H. O., \& Jesus, L. (2014). Composição específica e distribuição da comunidade de macrófitas aquáticas no reservatório de aimorés. Planta Daninha, 32(3), 475-482. https://doi.org/10.1590/S0100-8358201400030002.

Pivari, M. O., De Oliveira, V. B., Costa, F. M., Ferreira, R. M., \& Salino, A. (2011). Macrófitas aquáticas do sistema lacustre do Vale do Rio Doce, Minas Gerais, Brasil. Rodriguesia, 62(4), 759-770. https://doi.org/10.1590/s2175-78602011000400005.

Quadra, G. R., Roland, F., Barros, N., Malm, O., Lino, A. S., Azevedo, G. M., Thomaz, J. R., Andrade-Vieira, L. F., Praça-Fontes, M. M., Almeida, R. M., Mendonça, R. F., Cardoso, S. J., Guida, Y. S., \& Campos, J. M. S. (2019). Far-reaching cytogenotoxic effects of mine waste from the Fundão dam disaster in Brazil. Chemosphere, 215. https://doi.org/10.1016/j.chemosphere.2018.10.104.

Saiter, F. Z., Brown, J. L., Thomas, W. W., de Oliveira-Filho, A. T., \& Carnaval, A. C. (2016). Environmental correlates of floristic regions and plant turnover in the Atlantic Forest hotspot. Journal of Biogeography, 43(12), 2322-2331. https://doi.org/10.1111/jbi.12774.

Salvador, R. B., \& Cavallari, D. C. (2014). A new species of Leiostracus (Gastropoda, Pulmonata, Orthalicoidea) from Espírito Santo, Brazil. Iheringia, 104(3), 364-366. https://doi.org/10.1590/1678-476620141043364366.

Santos, O. S. H., Avellar, F. C., Alves, M., Trindade, R. C., Menezes, M. B., Ferreira, M. C., França, G. S., Cordeiro, J., Sobreira, F. G., Yoshida, I. M., Moura, P. M., Baptista, M. B., \& Scotti, M. R. (2019). Understanding the Environmental Impact of a Mine Dam Rupture in 

"Pesca e Aquicultura: Gestão, Política e Inovação", 63-84.

Brazil: Prospects for Remediation. Journal of Environmental Quality, 48(2). https://doi.org/10.2134/jeq2018.04.0168.

Silveira, H. (2001) SWOT. In: Inteligência Organizacional e Competitiva. Org. Kira Tarapanoff. Brasília. Ed. UNB.

Silveira, E. M. O., Cunha, L. I. F., Galvão, L. S., Withey, K. D., Acerbi Júnior, F. W., \& Scolforo, J. R. S. (2019a). Modelling aboveground biomass in forest remnants of the Brazilian Atlantic Forest using remote sensing, environmental and terrain-related data. Geocarto International, 0(0), 1-18. https://doi.org/10.1080/10106049.2019.1594394.

Silveira, E. M. O., Silva, S. H. G., Acerbi-Junior, F. W., Carvalho, M. C., Carvalho, L. M. T., Scolforo, J. R. S., \& Wulder, M. A. (2019b). Object-based random forest modelling of aboveground forest biomass outperforms a pixel-based approach in a heterogeneous and mountain tropical environment. International Journal of Applied Earth Observation and Geoinformation, 78 (December 2018), 175-188. https://doi.org/10.1016/j.jag.2019.02.004.

Raynaut, C., Zanoni, M., Lana, P. C. (2002). Desenvolvimento e meio ambiente: em busca da interdisciplinaridade. Pesquisas urbanas e rurais. Editora UFPR/UNESCO, Curitiba.

Viana, J. P. (2016). Os pescadores da bacia do rio Doce: subsídios para a mitigação dos impactos socioambientais do desastre da Samarco em Mariana, Minas Gerais. Nota Técnica IPEA, 11, 3-51.

Zago, V. C. P., das Dores, N. C., \& Watts, B. A. (2019). Strategy for phytomanagement in an area affected by iron ore dam rupture: A study case in Minas Gerais State, Brazil. Environmental Pollution, 249, 1029-1037. https://doi.org/10.1016/j.envpol.2019.03.060. 